\title{
Repositorios universitarios argentinos en coyuntura: desarrollo y perspectivas de sus gestores
}

\author{
Fushimi, Marcela*; Pené, Mónica Gabriela*; Sanllorenti, Ana María*; \\ Unzurrunzaga, Carolina ${ }^{\star}$
}

\section{Resumen}

Los repositorios institucionales desarrollados por las universidades son infraestructuras necesarias para garantizar el acceso a la literatura científica a toda la ciudadanía. Argentina, desde 2013, dispone de una ley nacional que insta a las entidades del sistema de ciencia y tecnología a generar repositorios de acceso abierto y a sus investigadores a depositar allí una copia de su trabajo. En este artículo se analiza su desarrollo y evolución en las universidades nacionales argentinas en relación con las políticas públicas implementadas a nivel nacional, las cuales se detallan en una cronología. A través de la observación directa de los sitios web de las universidades, se identifican los repositorios y otras iniciativas de acceso abierto y se sistematiza la información. Luego, mediante entrevistas, se indaga la perspectiva y opinión de sus gestores para conocer los modos en que se interrelacionan las políticas públicas con las realidades institucionales. Finalmente, se discute y reflexiona acerca de las particularidades de los repositorios en la coyuntura institucional y política.

Palabras clave: repositorios digitales; universidades nacionales; acceso abierto; Argentina; Ley 26.899

Los resultados expresados en este artículo son producto del trabajo realizado en el proyecto de investigación Repositorios digitales de acceso abierto en las universidades nacionales argentinas: Desarrollo, evolución y perspectivas de futuro (Código H040, período 2018-2019) financiado por la Universidad Nacional de La Plata que tuvo curso en el Instituto de Investigaciones en Humanidades y Ciencias Sociales que depende de la Universidad Nacional de La Plata y el CONICET (Argentina). Recibido el 16/11/2020, aprobado el $01 / 06 / 2021$ y publicado el 11/08/2021.

DOI: https://doi.org/10.33255/3262/924

Autoría: *Instituto de Investigaciones en Humanidades y Ciencias Sociales (UNLP - Conicet), Argentina. Contacto: mfushimi@fahce.unlp.edu.ar 


\title{
Current Situation of Argentine University Repositories: Features of Development and Manager's Perspectives
}

\begin{abstract}
The institutional repositories developed by universities are necessary infrastructures to guarantee access to scientific literature for all citizens. Argentina, since 2013, has a national law that obligues the entities of the Science and Technology System to generate open access repositories, and its researchers to deposit a copy of their work there. This article analyzes the development and evolution of these repositories in Argentine national universities in relation to public policies implemented at the national level, which are detailed in a chronology. Through direct observation of university websites, repositories and other open access initiatives are identified and information is systematized. Then, through interviews, the perspective and point of view of its managers are investigated to learn about the ways in which public policies are interrelated with institutional realities. Finally, the features of the repositories in the current institutional and political situation are discussed
\end{abstract}

Keywords: Digital Repositories; National Universities; Open Access; Argentina; Law 26.899

\section{Repositórios universitários argentinos em conjuntura. Desenvolvimento e perspectivas de seus gestores}

Os repositórios institucionais desenvolvidos pelas universidades são infraestruturas necessárias para garantir o acesso à literatura científica para todos os cidadãos. A Argentina, desde 2013, possui uma lei nacional que insta as entidades do sistema de ciência e tecnologia a gerar repositórios de acesso aberto e seus pesquisadores a depositar neles uma cópia de seus trabalhos. Este artigo analisa o seu desenvolvimento e evolução nas universidades nacionais argentinas em relação às políticas públicas implementadas a nível nacional, que são detalhadas em uma cronologia. Por meio da observação direta dos sites das universidades, os repositórios e outras iniciativas de acesso aberto são identificados e a informação é sistematizada. Em seguida, através de entrevistas, a perspectiva e a opinião de seus gestores são investigadas para conhecer as formas como as políticas públicas se inter-relacionam com as realidades institucionais. Por fim, discute-se e reflete-se sobre as particularidades dos repositórios na conjuntura institucional e política. Palavras-chave: repositórios digitais; universidades nacionais; Argentina; acesso aberto; Lei 26.899 


\section{Introducción}

El acceso a la literatura científica es fundamental para lograr el desarrollo social, cultural y económico de los países. Desde el movimiento internacional de acceso abierto (en adelante, AA) ${ }^{\underline{1}}$ se plantearon dos estrategias para conseguirlo: la publicación en revistas de acceso abierto -vía dorada- y el autoarchivo en repositorios digitales abiertos -vía verde-. En base a la teoría de la construcción social de la tecnología (Pinch y Bijker, 2008), podemos considerar como artefactos sociotécnicos a las infraestructuras que son generadas por los diferentes actores para disponibilizar la literatura en AA. Siguiendo esta línea, estudiar la participación de los distintos grupos sociales relevantes, como señala Guédon (2009), resulta vital para comprender el surgimiento y desarrollo de las iniciativas, conocer los significados que cada grupo le atribuye y evaluar su funcionamiento. Las universidades son uno de los actores claves del sistema de comunicación científica (Freitas y Leite, 2019), las cuales se encargan de gestionar la investigación, disponer de infraestructuras científico-tecnológicas para sostenerla y dar a conocer los resultados. Como tales, han sido agentes que a nivel mundial concretaron la construcción de repositorios, haciendo realidad la vía verde del acceso abierto.

En Argentina, el ámbito de las universidades nacionales de gestión pública (en lo sucesivo, UUNN) se destaca por la presencia de una cantidad notable de iniciativas de AA muy variadas y heterogéneas que han sido relevadas en investigaciones previas (De Volder, 2008; Fushimi y Banzato, 2010; Pené, Unzurrunzaga y Borrell, 2016; Fushimi, 2018; Unzurrunzaga et al., 2019; Fushimi y Unzurrunzaga, 2020). La ley nacional 26.899 (2013), que marcó un hito en el avance de las políticas de acceso abierto en Argentina y en la región, promueve la creación y el fomento de los repositorios institucionales como instrumentos a través de los cuales se pueda acceder a la producción científica generada con fondos públicos.

Estudios realizados con antelación a la sanción de la ley antes referida mostraron que el conocimiento de las y los investigadores sobre los repositorios era bajo, incluso que un grupo importante desconocía su existencia, aunque resultaba alentador que se expresaran a favor de los lineamientos generales del acceso abierto (Bongiovani y otros, 2014). Posteriormente, Fushimi (2018) señaló que en el desarrollo de los repositorios en las UUNN fue el sector bibliotecario el que tuvo a su cargo la construcción de estos artefactos -en la mayor parte de los casos-, mientras que las y los docentes/investigadores tuvieron en general una baja participación, que sumada a las prácticas disciplinares y las políticas de evaluación, derivaron en escaso compromiso y 
baja adhesión al autoarchivo. Características que también fueron observadas en parte por investigaciones recientes que toman como caso de estudio a la Universidad Nacional de La Plata (Mazza, 2019) y a la Universidad Nacional de Entre Ríos (Andrés et al., 2020). Por otra parte, Nakano y Azrilevich (2017) señalaban que menos de la mitad de las UUNN habían presentado avances en torno a la implementación de la ley.

Esta situación y la constatación de la coexistencia de una gran variedad y cantidad de iniciativas con fines similares a los repositorios en las UUNN justificó una indagación específica para contemplar el panorama completo de lo que estaba sucediendo en ese ámbito. Para esto, realizamos una cronología de las políticas de acceso abierto que se llevaron a cabo a nivel nacional y que contextualizan las iniciativas detectadas. Luego, describimos la situación de los repositorios en relación con el resto de las iniciativas e identificamos aspectos que marcan su desarrollo y evolución. $Y$ por último, analizamos las percepciones y opiniones de los gestores de los repositorios -a quienes consideramos actores clave- a fin de dar cuenta de los modos en que se interrelacionan las políticas públicas con las realidades en las instituciones. La reunión de estos elementos nos permitió comprender y reflexionar acerca de las particularidades de estos artefactos en la coyuntura institucional y política argentina.

\section{Aspectos metodológicos}

Para desarrollar la investigación, planteamos una combinación de técnicas de análisis cualitativo y trabajamos con tres conjuntos de datos que nos permitieron tener un panorama de lo que sucedía en las 65 instituciones universitarias de gestión pública argentinas asociadas al Consejo Interuniversitario Nacional (CIN). El primero surgió de una observación directa de sus sitios web y el de sus facultades, realizada entre los meses de febrero y mayo de 2019 en busca de iniciativas de AA y de repositorios institucionales. Consideramos iniciativas de acceso abierto a todas aquellas páginas o portales web que reúnen producción científica y/o académica institucional y la ofrecen para lectura y/o descarga de forma gratuita y abierta, aunque no adhieran expresamente al movimiento AA, no adopten una licencia de distribución explícita² o utilicen un software específico. Registramos en una matriz de datos construida ad hoc distintas variables de cada iniciativa: región, universidad, nombre y tipo de iniciativa, estado, antigüedad, normativa relacionada, nivel de dependencia, software de gestión, tipología, cantidad y formatos de documentos, temáticas comprendidas, nombres de responsables y sus correos de contacto. Los tipos de iniciativa con- 
siderados a priori fueron: repositorios de distinta naturaleza (institucionales, temáticos/disciplinares, de fuentes de investigación, de datos primarios, y de objetos de aprendizaje), editoriales universitarias que disponían material en su web, portales de libros abiertos, portales de revistas abiertas ${ }^{3} y$ otras iniciativas similares no clasificadas que abarcan bibliotecas digitales, páginas web y sitios diversos con producción científico-académica de descarga gratuita.

El segundo conjunto de datos analizados fueron las normativas y los textos informativos relacionados con cada iniciativa localizada en los sitios web respectivos. De estos, realizamos una clasificación básica en la que identificamos a las políticas de acceso abierto del resto, que eran documentos tales como reglamentaciones u ordenanzas de creación, políticas de funcionamiento, instructivos y otros materiales que dan cuenta de las prácticas.

Por último, para conformar el tercer conjunto de datos, realizamos un total de cuarenta entrevistas entre octubre de 2019 y julio de 2020 a quienes gestionan los repositorios para tener su perspectiva y opinión. La guía de preguntas se organizó en cinco ejes: 1) la influencia que tuvieron las políticas públicas nacionales en la creación de los repositorios; 2) la recepción de la legislación -y de los repositorios- entre las y los investigadores; 3 ) la articulación de los repositorios con otras iniciativas existentes en las instituciones; 4) la existencia de políticas de AA y los obstáculos para la adecuación a la ley; y 5) el funcionamiento del SNRD. La guía se envió por correo electrónico y las entrevistas se efectuaron de manera sincrónica -presencial o virtual- 0 bien asincrónica -por escrito o por audio-. La tasa de respuesta fue del $65 \%$ (40 de los 61 repositorios identificados).

\section{Políticas de acceso abierto en Argentina}

Si bien es cierto que previo a la sanción de la ley 26.899 ya existían algunos repositorios, estos constituían iniciativas aisladas, en su mayoría lideradas por bibliotecas universitarias, cuyas posibilidades de crecimiento dependían del apoyo institucional (De Volder, 2008). En el Gráfico 1, situamos en una línea de tiempo las acciones desarrolladas desde el Estado nacional para la promoción de los repositorios y que, desde nuestro punto de vista, constituyen las políticas de AA en Argentina. 


\section{Acciones de promoción de la vía verde}

Convocatoria a actores involucrados en la gestión de repositorios en Argentina

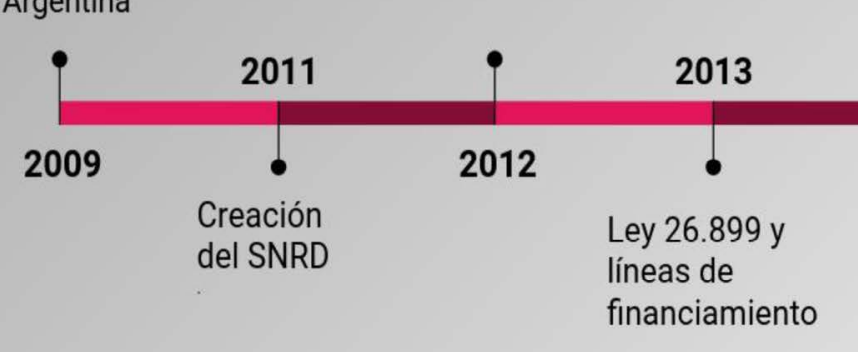

Reglamentación Ley 26.899

Gráfico 1. Línea de tiempo de políticas AA emprendidas a nivel nacional en Argentina

La primera acción realizada por el gobierno nacional se observa en 2009, cuando el recientemente creado Ministerio de Ciencia, Tecnología e Innovación Productiva (MinCyT) convocó a reunión a diversos actores de las UUNN y de los organismos de CyT (Ciencia y Tecnología) que estaban gestionando repositorios, lo que derivó en la conformación de comisiones temáticas de trabajo (Lattuada y Giba, 2014). A partir de allí se inició una labor en conjunto que condujo, en 2011, a la creación del Sistema Nacional de Repositorios Digitales (SNRD), con el objetivo de «conformar una red interoperable de repositorios digitales en ciencia y tecnología, a partir del establecimiento de políticas, estándares y protocolos comunes a todos los integrantes del Sistema» (Res. 469/2011). Como parte de su estructura organizativa se constituyó un Comité de Expertos, que tiene entre sus funciones planificar, proponer y coordinar acciones, directrices y políticas en relación con el desarrollo de los repositorios, con miras a maximizar su potencial. En resumen, el SNRD brinda apoyo técnico y financiero, además de visibilidad de la producción científica, a través de un portal que es cosechado a nivel regional e internacional por los portales LA Referencia y OpenAire ${ }^{4}$, respectivamente.

Otra de las acciones promovidas desde el SNRD fueron los Proyectos de Investigación Científica y Tecnológica Orientados (PICT-O) en el marco del convenio suscrito entre el MinCyT y el CIN, convocados en el año 2010 y ejecutados durante el período 2012-2013, que significaron un primer salto en el ámbito universitario al poner en agenda el tema en cuestión. De hecho, los seis proyectos PICT-O CIN aglutinaron a las UUNN de las regiones Bonaerense, Metropolitana, Centro-Este, Centro-Oeste, Sur y Noroeste, dando lugar al desarrollo de muchos de los repositorios actuales (Fushimi, 2018). 
Bongiovani y Nakano (2011), al presentar la experiencia de articulación y coordinación llevadas adelante por el MinCyT, señalan que las distintas estrategias emprendidas desde el Estado constituían la muestra de «una política de articulación interinstitucional» (p. 176) que benefició a través del SNRD tanto a la comunidad académica como a la ciudadanía. Se amplió la difusión y visibilidad de la producción nacional, se mejoró su accesibilidad y se transparentaron los procesos, optimizando la utilización de los fondos públicos.

Por otra parte, desde el SNRD se elaboró el proyecto de la futura ley 26.899 de repositorios y el de su posterior reglamentación, que fueron aprobadas respectivamente en 2013 y 2016. En esta ley, como mencionamos antes, se promueve la denominada «vía verde» como el mecanismo para alcanzar el acceso abierto a la producción científica generada con fondos públicos, y se determina que la literatura científica y los datos primarios de las investigaciones financiadas con fondos públicos deben estar en acceso abierto a través de repositorios digitales que las instituciones del sistema nacional de CyT están obligadas a crear y gestionar. Asimismo, se exige a las y los investigadores el depósito de sus producciones y de los datos primarios que generen en los mencionados repositorios. Y finalmente obliga a las agencias de financiamiento a requerir a las y los investigadores un plan que garantice la disponibilidad pública de los resultados de sus investigaciones.

En el marco del SNRD, además se pusieron en marcha líneas de financiamiento con fondos provenientes del Banco Interamericano de Desarrollo administrados por la Agencia Nacional de Promoción de la Investigación, el Desarrollo Tecnológico y la Innovación del MinCyT, tanto para la creación como para el fortalecimiento de repositorios en todas las instituciones que integran el sistema de CyT.

\section{Estado de situación de los repositorios en las UUNN}

Hacia mediados de 2019 localizamos un total de 153 iniciativas de AA en las 65 UUNN que componían el sistema público universitario de ese momento $\underline{5}$ (Gráfico 2). De ese total, 53 (35\%) eran repositorios institucionales como los promovidos por la ley 26.899 , mientras que las restantes iniciativas correspondían a una variedad de artefactos que fueron creados en las universidades con el objetivo de ofrecer en la web la literatura académico-científica producida en su ámbito. Algunas de estas eran editoriales universitarias desde donde pueden descargarse o leerse gratuitamente documentos y libros (19\%). Existía, asimismo, una cantidad importante de portales de revistas científicas (20\%) y otra no menor de libros académicos (3\%), también disponibles de manera abierta y/o gratuita. 
Hallamos varias iniciativas que agrupamos como sin clasificar (18\%), tales como sitios web y/o bibliotecas digitales que comparten material institucional de forma gratuita en Internet, sin usar un software específico ni una organización técnica profesional, pero que consideramos demuestran el interés y predisposición de la institución y sus grupos involucrados hacia la apertura y la difusión de su producción. Por su parte, los repositorios de datos fueron los grandes ausentes; solo localizamos una iniciativa específica en la UN La Plata (UNLP) vinculada con la resolución de una problemática local. Asimismo encontramos que en 4 de los 53 repositorios institucionales se mencionaba en su web la posibilidad de autoarchivar conjuntos de datos en el repositorio de literatura (UNLP, UN Mar del Plata-UNMdP-, UN Córdoba-UNC-y UN Río Negro-UNRN-). Por otro lado, al contrastar las iniciativas de repositorios (vía verde) con las de publicación (vía dorada), pudimos corroborar que la edición de libros y de revistas científicas es una cuestión arraigada en las universidades ( $42 \%$ de las iniciativas).

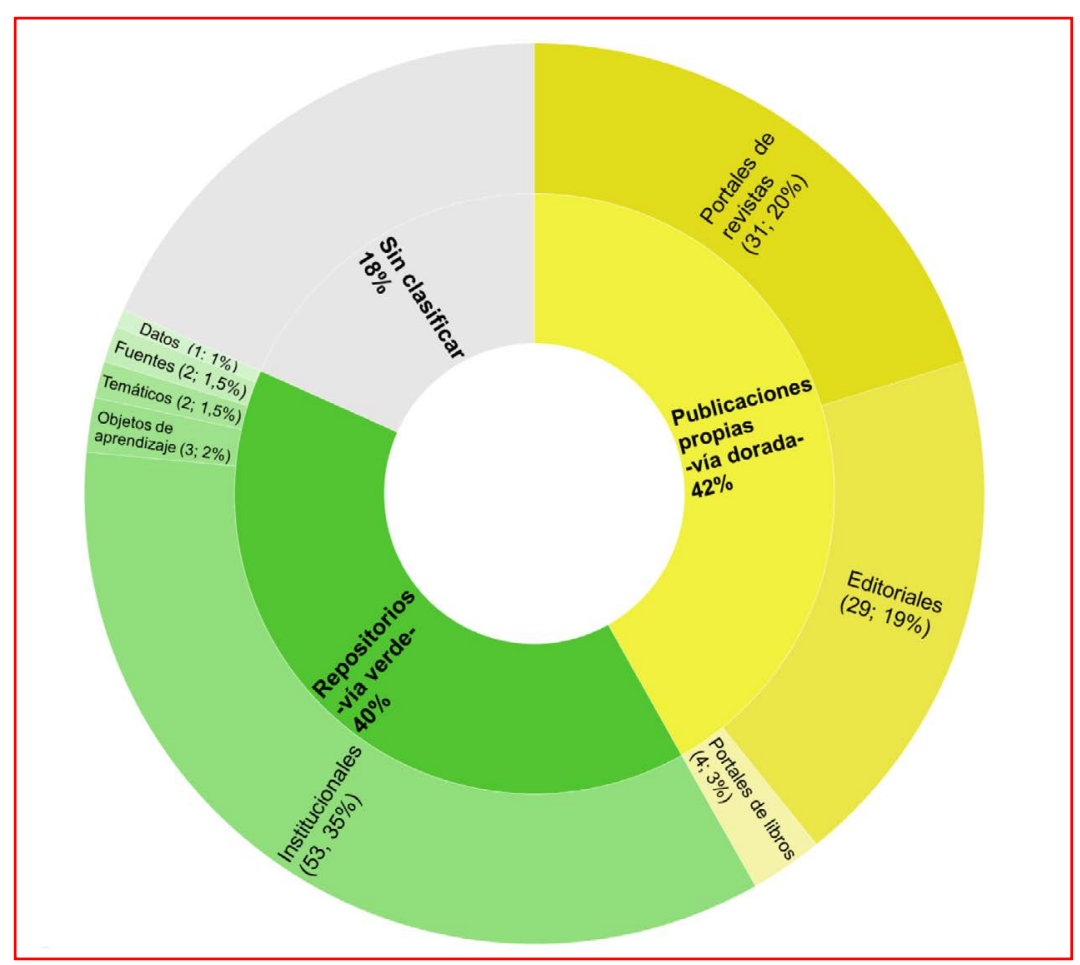

Gráfico 2. Iniciativas de AA en UUNN por tipo ( $n=153)$

Si bien detectamos que la mayor parte de estas iniciativas eran generales para toda la universidad (56\%), encontramos una cantidad importante de desarrollos a nivel de facultades, departamentos o instancias de menor jerarquía que, lejos de ser un hecho aislado, se presenta en más de la mitad de las instituciones. Como puede verse en la Tabla 1, el número heterogéneo de iniciativas 
aumenta considerablemente en las universidades con estructuras más complejas -como son las de UNLP, UNMdP, U Buenos Aires (UBA) y UNC-, mientras que para varias de reciente creación el número es menor o no se detectaron iniciativas ${ }^{6}$. Observamos además la confluencia de escuelas universitarias de bibliotecología en las UUNN con un mayor número de iniciativas, lo que podría estar indicando que el hecho de contar con profesionales de la información formados en la propia institución favoreció el surgimiento de tales proyectos (casos UBA, UNLP, UNMdP, UNC y UN de Misiones -UNaM-).

Tabla 1. Distribución de iniciativas AA por UUNN (febrero-mayo 2019)

\begin{tabular}{|c|c|c|c|c|c|c|c|c|c|c|c|c|c|c|c|c|}
\hline \multirow[b]{3}{*}{ UUNN } & \multicolumn{7}{|c|}{ Repositorios -vía verde- } & \multicolumn{6}{|c|}{ Publicaciones propias -vía dorada- } & \multirow{2}{*}{\multicolumn{2}{|c|}{ Sin clasificar }} & \multirow{3}{*}{ Total } \\
\hline & \multicolumn{2}{|c|}{ Institucionales } & \multirow{2}{*}{$\begin{array}{c}\text { Temáticos } \\
\text { Esp. } \\
\end{array}$} & \multirow{2}{*}{\begin{tabular}{|c|} 
Fuentes \\
Esp.
\end{tabular}} & \multirow{2}{*}{\begin{tabular}{|c|} 
Datos \\
Esp. \\
\end{tabular}} & \multicolumn{2}{|c|}{ O. aprendizaje } & \multicolumn{2}{|c|}{ Editoriales } & \multicolumn{2}{|c|}{ P. de revistas } & \multicolumn{2}{|c|}{ P. de libros } & & & \\
\hline & \begin{tabular}{|l|} 
Gral. \\
\end{tabular} & Esp. & & & & Gral. & Esp. & Gral. & Esp. & Gral. & Esp. & Gral. & Esp. & Gral. & Esp. & \\
\hline UN La Plata & 1 & 3 & & 1 & 1 & & 1 & 1 & 2 & 1 & 2 & 1 & 1 & & 2 & 17 \\
\hline U Buenos Aires & 1 & 6 & & & & & & & 2 & & 4 & & & & 1 & 14 \\
\hline UN Mar del Plata & & 4 & & & & & & 1 & & 1 & 3 & & 2 & 1 & 1 & 13 \\
\hline UN Córdoba & 1 & 1 & 1 & & & & 1 & & 2 & 1 & & & & 3 & 1 & 11 \\
\hline UN Rosario & 1 & & & & & & & 1 & & & & & & 1 & 3 & 6 \\
\hline UN Comahue & 1 & 2 & & & & & & & & 1 & & & & & 2 & 6 \\
\hline UN Misiones & 1 & 2 & & & & & & 1 & & & 1 & & & & 4 & 5 \\
\hline UN San Martín & 1 & & & & & & & 1 & & 1 & & & & & 1 & 4 \\
\hline UN Salta & 1 & & 1 & & & & & & & 1 & & & & & 1 & 4 \\
\hline UN Patagonia Austral & & & & & & & & & & 2 & & & & 1 & 1 & 4 \\
\hline UN Centro Prov. Buenos Aires & 1 & & & 1 & & & & & & & 1 & & & & 1 & 4 \\
\hline UN Sur & 1 & & & & & & & 1 & & & 1 & & & & & 3 \\
\hline UN Río Cuarto & & & & & & & & 1 & & & 1 & & & 1 & & 3 \\
\hline UN Nordeste & 1 & & & & & & & 1 & & 1 & & & & & & 3 \\
\hline UN La Pampa & 1 & 1 & & & & & & & & 1 & & & & & & 3 \\
\hline UN Litoral & 1 & & & & & & & 1 & & 1 & & & & & & 3 \\
\hline UN Entre Rios & 1 & & & & & & & & & 1 & & & & 1 & & 3 \\
\hline UN Defensa Nacional & 1 & 1 & & & & & & 1 & & & & & & & & 3 \\
\hline UN Cuyo & 1 & & & & & & & - & & 1 & & & & & 1 & 3 \\
\hline U Tecnológica Nacional & 1 & & & & & & & 1 & & & & & & & & 2 \\
\hline UN Tucumán & 1 & & & & & & & & & & & & & & 1 & 2 \\
\hline UN San Luis & & & & & & & & 1 & & 1 & & & & & & 2 \\
\hline UN Río Negro & 1 & & & & & & & 1 & & & & & & & & 2 \\
\hline UN Rafaela & 1 & & & & & & & 1 & & & & & & & & 2 \\
\hline UN Quilmes & 1 & & & & & & & 1 & & & & & & & & 2 \\
\hline UN Patagonia San Juan Bosco & & & & & & 1 & & 1 & & & & & & & & 2 \\
\hline UN Moreno & 1 & & & & & & & 1 & & & & & & & & 2 \\
\hline UN La Rioja & & & & & & & & 1 & & 1 & & & & & & 2 \\
\hline UN La Matanza & 1 & & & & & & & & & 1 & & & & & & 2 \\
\hline UN Lanus & 1 & & & & & & & & & 1 & & & & & & 2 \\
\hline UN Jujuy & 1 & & & & & & & 1 & & & & & & & & 2 \\
\hline UN Pedagógica Nacional & & & & & & & & 1 & & & & & & 1 & & 2 \\
\hline UN Catamarca & & 1 & & & & & & 1 & & & & & & & & 2 \\
\hline U Provincial del Sudoeste & & & & & & & & 1 & & & & & & & & 1 \\
\hline UN Villa María & 1 & & & & & & & & & & & & & & & 1 \\
\hline UN Tres de Febrero & & & & & & & & & & & 1 & & & & & 1 \\
\hline UN Santiago del Estero & 1 & & & & & & & & & & & & & & & 1 \\
\hline UN José C. Paz & & & & & & & & 1 & & & & & & & & 1 \\
\hline UN Luján & 1 & & & & & & & & & & & & & & & 1 \\
\hline UN General Sarmiento & & & & & & & & & & & & & & 1 & & 1 \\
\hline UN Chilecito & & & & & & & & & & & & & & 1 & & 1 \\
\hline UN Avellaneda & 1 & & & & & & & & & & & & & & & 1 \\
\hline UN Arturo Jauretche & & & & & & & & & & & & & & 1 & & 1 \\
\hline UN de las Artes & 1 & & & & & & & & & & & & & & & 1 \\
\hline U Autónoma de Entre Ríos & 1 & & & & & & & & & & & & & & & 1 \\
\hline IU Gendermería Nacional & 1 & & & & & & & & & & & & & & & 1 \\
\hline Total & 32 & 21 & 2 & 2 & 1 & 1 & 2 & $\mid 23$ & 6 & 17 & 14 & 1 & 3 & 12 & 16 & 153 \\
\hline
\end{tabular}

Referencias: Gral.: Iniciativa de carácter general para toda la universidad; Esp.: Iniciativa específica de una facultad, instituto o proyecto; O. aprendizaje: Objetos de aprendizaje; P. de revistas: Portal de revista; P. de libros: Portal de libros. U: Universidad; UN: Universidad Nacional; IU: Instituto universitario. 
En cuanto a los repositorios institucionales en particular, pudimos observar que de los 53 detectados, 46 estaban en funcionamiento y tan solo 33 de ellos estaban adheridos al SNRD. Respecto a su evolución, en el Gráfico 3 agrupamos los repositorios por su año de puesta en funcionamiento y marcamos la línea de tendencia que -aunque con altibajos- resulta positiva. Tomando como hito la ley, distinguimos dos etapas en la evolución de los repositorios. Una inicial que va de 2003 a 2013, en la que surgen los primeros repositorios apenas poco tiempo después de las declaraciones fundacionales del $A A^{7}$, creándose dieciséis repositorios en diez años. La otra etapa, que va desde 2014 a 2019, está signada por la política pública, donde en tan solo seis años se pusieron en funcionamiento los treinta repositorios restantes, llegando a triplicar su número. Asimismo constatamos que en el $60 \%$ de los casos, las bibliotecas o servicios de información institucionales están involucrados en su desarrollo y mantenimiento.

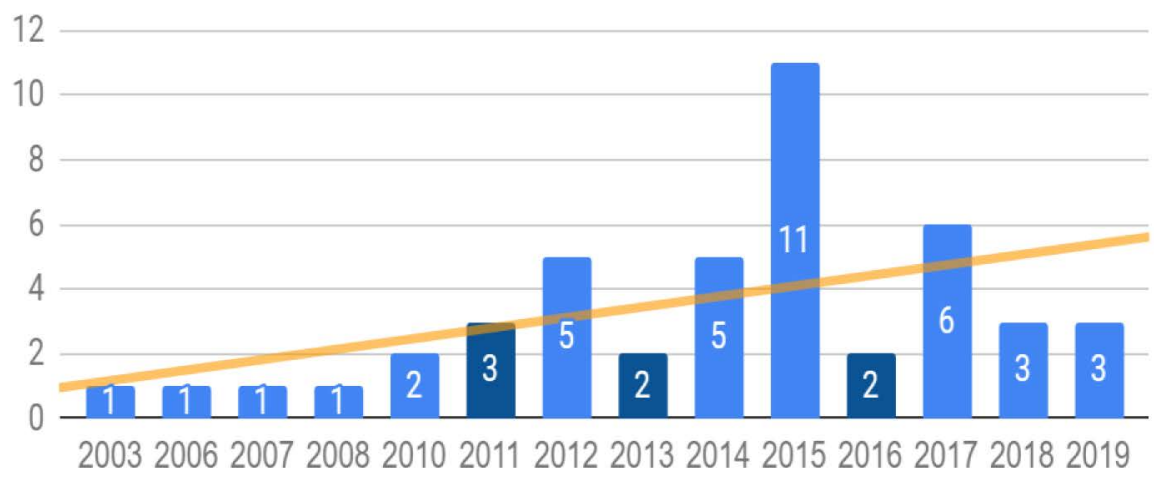

Gráfico 3. Cantidad de repositorios institucionales creados por año (período 2003-2019) ( $n=46)$ Nota: En azul oscuro se señalan los años en que hubo políticas concretas: creación del SNRD (2011), aprobación de la ley 26.899 (2013) y su reglamentación (2016).

Otro aspecto para complementar este análisis es el tamaño de los repositorios, medido en cantidad de objetos digitales incluidos, dato que permite evaluar su evolución en relación con el modelo de desarrollo adoptado. El orden de la Tabla 2 muestra en qué medida variables como la edad y el tamaño influyen en la posición de cada repositorio si calculamos la media de documentos incorporados por año. En concreto, vemos que el repositorio central de la UBA aparece en primer lugar aunque tenga casi la mitad de documentos que el SEDICI de la UNLP. Esto sugiere que el modelo de gestión descentralizado y articulado adoptado por la UBA -sumado a la producción 
esperable por tratarse de la universidad más grande del país-con un repositorio central que cosecha los recursos disponibles en los cinco repositorios de sus facultades, le ha permitido conseguir una importante ingesta por año. En el caso de la UNLP, que también sigue un modelo descentralizado aunque con menor articulación entre sus repositorios (Mazza, 2019), se observa que la media de documentos ingresados por año es menor a pesar de haber sido el primero en ponerse en funcionamiento y el que mayor tamaño ha alcanzado. Por otra parte, es interesante contrastar lo anterior con los casos de la UNC y la UN Rosario (UNR) -consideradas asimismo grandes-, ambas con modelos de desarrollo centralizados, con repositorios creados antes de la sanción de la ley y, sin embargo, con un ritmo de crecimiento anual más lento, lo que podría interpretarse como una mayor dificultad para avanzar con un único repositorio para toda la universidad.

Por otra parte, destacan otras instituciones de educación superior de menor tamaño con repositorios creados luego de sancionada la ley, que avanzaron sustancialmente en los últimos años en la disposición en acceso abierto de una cantidad considerable de producción (UN Defensa Nacional -UNDEF-, UN La Pampa -UNLPAM-). En contraposición, hallamos que algunos repositorios, gestados incluso en el primer período, parecen haber tenido distintos obstáculos para constituirse como una infraestructura para propiciar el acceso abierto dentro de la institución.

Tabla 2. Repositorios institucionales en funcionamiento en las UUNN según media de documentos por años de funcionamiento $(n=46)$

\begin{tabular}{l|l|c|c|c|c}
\hline \multicolumn{1}{|c|}{ Sigla UUNN } & \multicolumn{1}{|c|}{ Nombre iniciativa } & $\begin{array}{c}\text { Año puesta en } \\
\text { funcionamiento }\end{array}$ & Edad & $\begin{array}{c}\text { Cantidad de } \\
\text { documentos }\end{array}$ & $\begin{array}{c}\text { Media de } \\
\text { documentos } \\
\text { por año }\end{array}$ \\
\hline UBA & $\begin{array}{l}\text { RDI-UBA Repositorio Digital Insti- } \\
\text { tucional }\end{array}$ & 2014 & 5 & 43372 & 8674 \\
\hline UNLP & $\begin{array}{l}\text { SEDICI Servicio de Difusión de la } \\
\text { Creación Intelectual }\end{array}$ & 2003 & 16 & 73064 & 4567 \\
\hline UBA. FCEN & Biblioteca Digital & 2010 & 9 & 22115 & 2457 \\
\hline UBA. FFL & Filo Digital & 2015 & 4 & 9334 & 2334 \\
\hline UNLP. FaHCE & Memoria Académica & 2007 & 12 & 26003 & 2167 \\
\hline UNDEF & Repositorio Digital Universitario & 2018 & 1 & 1729 & 1729 \\
\hline UNLP. FCNyM & Naturalis & 2012 & 7 & 9583 & 1369 \\
\hline UBA.FMED & Memoria Institucional & 2013 & 6 & 8112 & 1352 \\
\hline UBA. FCE & Biblioteca Digital & 2015 & 4 & 5347 & 1337 \\
\hline UNLPAM & $\begin{array}{l}\text { Repositorio Digital de Acceso } \\
\text { Abierto }\end{array}$ & 2015 & 4 & 5271 & 1318 \\
\hline
\end{tabular}


Fushimi, Marcela; et al. I Repositorios universitarios argentinos en coyuntura...

\begin{tabular}{|c|c|c|c|c|c|}
\hline UNR & $\begin{array}{l}\text { RepHipUNR: Repositorio } \\
\text { Hipermedial }\end{array}$ & 2008 & 11 & 10994 & 999 \\
\hline UTN & Repositorio Institucional Abierto & 2016 & 3 & 2905 & 968 \\
\hline UNC & Repositorio Digital & 2011 & 8 & 6794 & 849 \\
\hline UBA. FA & FAUBA Digital & 2012 & 7 & 5583 & 798 \\
\hline UNCuyo & Biblioteca Digital & 2006 & 13 & 9819 & 755 \\
\hline UNA & RepositoriolnstitucionalDigital(RID) & 2017 & 2 & 1461 & 731 \\
\hline UnCoMA & Lenguas. Biblioteca digital & 2019 & 0,5 & 238 & 238 \\
\hline UNICEN & $\begin{array}{l}\text { RIDAA: Repositorio Institucional } \\
\text { Digital de Acceso Abierto }\end{array}$ & 2015 & 4 & 1754 & 439 \\
\hline UNL & Biblioteca Virtual & 2011 & 8 & 3053 & 382 \\
\hline UNRN & Repositorio Digital Institucional & 2015 & 4 & 1481 & 370 \\
\hline UNS & Repositorio institucional de la UNS & 2015 & 4 & 1412 & 353 \\
\hline UNMdP. FCEYS & \begin{tabular}{|l|l} 
Nülan \\
\end{tabular} & 2010 & 9 & 3126 & 347 \\
\hline UNNE & RIUNNE & 2017 & 2 & 670 & 335 \\
\hline UNDEF & CEFA Digital & 2015 & 4 & 1031 & 258 \\
\hline UNVM & $\begin{array}{l}\text { Repositorio Digital Universidad } \\
\text { Nacional de Villa María }\end{array}$ & 2015 & 4 & 1010 & 253 \\
\hline UNQ & $\begin{array}{l}\text { RIDAA: Repositorio Institucional Di- } \\
\text { gital de Acceso Abierto de la UNQ }\end{array}$ & 2015 & 4 & 946 & 237 \\
\hline UNC. FA & $\begin{array}{l}\text { MAPA Repositorio digital de la } \\
\text { Facultad de Artes }\end{array}$ & 2018 & 1 & 186 & 186 \\
\hline UNLP. FAU & Biblioteca Digital Arq.Hilario Zalba & 2017 & 2 & 367 & 184 \\
\hline UNMdP. FH & HumaDoc & 2014 & 5 & 868 & 174 \\
\hline UnaM & Argos & 2014 & 5 & 682 & 136 \\
\hline UnaM & Repositorio institucional digital & 2018 & 1 & 121 & 121 \\
\hline UnCoMA & Repositorio digital FATU & 2012 & 7 & 738 & 105 \\
\hline UNSe & $\begin{array}{l}\text { Repositorio Digital Biblioteca } \\
\text { Central UNSE }\end{array}$ & 2017 & 2 & 173 & 87 \\
\hline UNMdP. Psico & RPsico & 2012 & 7 & 605 & 86 \\
\hline UNLa & $\begin{array}{l}\text { Repositorio Digital Institucional } \\
\text { José María Rosa }\end{array}$ & 2012 & 7 & 579 & 83 \\
\hline UNLu & $\begin{array}{l}\text { Repositorio digital institucional } \\
\text { REDIUNLu }\end{array}$ & 2017 & 2 & 164 & 82 \\
\hline UnCoMA & RDI-UNCo & 2014 & 5 & 352 & 70 \\
\hline UNSAM & Repositorio institucional & 2015 & 4 & 258 & 65 \\
\hline UBA. FI & Repositorio institucional & 2017 & 2 & 116 & 58 \\
\hline UNLPAM & $\begin{array}{l}\text { ReDi: Repositorio Digital de la } \\
\text { FCEYN - UNLPAM }\end{array}$ & 2014 & 5 & 203 & 41 \\
\hline UNDAV & $\begin{array}{l}\text { RDD Repositorio Documental y de } \\
\text { datos }\end{array}$ & 2016 & 3 & 114 & 38 \\
\hline UNT & $\begin{array}{l}\text { RIUNT - Repositorio Institucional } \\
\text { de la Universidad Nacional de } \\
\text { Tucumán }\end{array}$ & 2013 & 6 & 140 & 23 \\
\hline UNLAM & Repositorio Digital UNLaM & 2011 & 8 & 94 & 12 \\
\hline IUGNA & REDIG & 2019 & 0,5 & 4 & 4 \\
\hline UNER & $\begin{array}{l}\text { RIUNER. Repositorio Institucional } \\
\text { de la Universidad Nacional de } \\
\text { Entre Ríos }\end{array}$ & 2015 & 4 & 17 & 4 \\
\hline UNJu & RiUNJU (Amauta) & 2019 & 0.5 & 2 & 2 \\
\hline
\end{tabular}




\section{Perspectivas de gestores de repositorios}

A continuación, analizamos las opiniones brindadas en las cuarenta entrevistas realizadas a quienes gestionan los distintos tipos de repositorios en relación con los ejes planteados para el estudio. Cabe mencionar que introducimos los resultados de la categorización de los documentos hallados en el relevamiento para completar el análisis del cumplimiento de los requerimientos de la ley.

\subsection{Influencia de las políticas públicas}

La mayoría de los gestores entrevistados concuerda en que la ley ha influenciado de alguna manera al repositorio, ya sea facilitando su creación, dando el impulso necesario al proyecto existente para que pueda concretarse, o bien estableciendo un marco normativo para la puesta en marcha del repositorio, otorgando institucionalidad a este tipo de iniciativas. Varios gestores califican la aprobación de la ley como «muy positiva», «determinante», «fundamental», «un puntapié inicial», y señalan la importancia de esta para la introducción del tema en la comunidad académica:

La ley fue un hito muy importante más que nada para impulsar el acceso abierto, generar conciencia en la necesidad y obligatoriedad del autoarchivo (aunque esto sea muy lento). También, al ser un instrumento nacional, ordena los principios que rigen a más bajo nivel. (E14)

Para los repositorios desarrollados a posteriori de la sanción de la ley, sus gestores señalan que esta cumplió un rol indispensable para su creación por el «marco legal necesario» que ofrecía ante las autoridades:

La ley 26.899 tuvo una influencia decisiva en la creación del repositorio, porque en base a la existencia de esa ley, el Consejo Superior casi en forma inmediata aprobó la resolución creando el repositorio de la universidad. (E34)

La ley de repositorios le dio un impulso importante, fue un marco en el que establecerse y apoyarse para las normativas siguientes y para conseguir el apoyo y el compromiso institucional de las autoridades en esos momentos. (E36)

Asimismo, se evidencia su efecto directo en el desarrollo de los repositorios que, proyectados desde hacía tiempo, aún no habían sido aprobados por las autoridades de sus propias instituciones. En este sentido, los gestores 
marcaron que aceleró dichos procesos, a la vez que favoreció la asignación de recursos para llevar adelante el proyecto:

La ley 26.899 tuvo una influencia muy marcada en la creación, teniendo en cuenta que desde 2009 había un anteproyecto de creación de un repositorio dando vueltas por las oficinas del Rectorado, ante la mirada indiferente de las autoridades... hasta que luego de la sanción volvimos a insistir con un proyecto más amplio esta vez, y el mismo fue aprobado a finales del 2014. (E29)

Fue un gran impulso, al momento de la sanción de la ley el repositorio estaba en construcción y al año siguiente se inauguró. Todo el proceso se desarrolló en el marco de la existencia del anteproyecto de ley y su posterior sanción. (E33)

Por otro lado, los gestores de repositorios que existían previamente destacaron la importancia de la ley como un instrumento legal que ofrece un marco normativo para la puesta en funcionamiento y/o fortalecimiento del $\mathrm{RI}$, siendo una herramienta eficaz para favorecer la aprobación de normativas y el posicionamiento en la institución:

Muy positiva. Permitió apoyar la continuidad del proyecto e incorporarlo como tema en los planes de gestión por fuera de la órbita de la biblioteca. Los instrumentos legales han sido claves para promover y darle entidad y sostenibilidad al proyecto. (E10)

En nuestra institución la sanción de la ley promovió un número de resoluciones de nuestro Consejo Superior y demás para la formalización de las distintas actividades que veníamos realizando. En ese sentido nos ayudó a sensibilizar a diversos actores y, en particular a nuestro Consejo Superior, sobre esta temática, y es por eso que como reflejo de la sanción de la ley fue que aparecieron algunas resoluciones y reglamentaciones internas. (E17)

Por su parte, cinco gestores señalaron que la ley no implicó diferencias en el funcionamiento del repositorio -que ya existía previo a su sanción- ni en el comportamiento de los miembros de la institución. Entre los motivos mencionados se encuentran: tipología documental no contemplada por la ley -objetos de aprendizaje- falta de compromiso institucional por parte de las autoridades; y mecanismos de evaluación de la ciencia que exigen al investigador publicar en revistas prestigiosas que no habilitan el depósito de su trabajo en el repositorio institucional. 


\subsection{Percepción de la ley entre quienes investigan}

La mayoría de los gestores percibe que el grado de conocimiento del acceso abierto y del repositorio entre las y los docentes-investigadores no es homogéneo y lo califican como «bajo», «parcial» o «escaso»; respecto de la ley y sus implicancias, lo consideran aún menor:

A pesar de las distintas instancias de sensibilización realizadas, creo que la comunidad target no conoce la norma, no la ha leído y reflexionado sobre ella. Sí saben de su existencia por lo recién comentado, y adhieren pasivamente porque les interesa la difusión y visibilidad de su producción científica. (E23)

Un grupo menor (siete casos) consideró que su comunidad investigativa tenía conocimiento de la legislación vigente y en algunos casos asociaron esto al efecto de sus acciones de difusión:

La comunidad de docentes investigadores tiene un conocimiento suficiente, dado que desde las distintas áreas de la institución, la biblioteca, entre ellas, realizan -y continúa realizando- difusión y divulgación sobre la ley y sus implicancias. (E3)

En este sentido, la mitad de las y los gestores mencionaron haber realizado distintas instancias de sensibilización -«concientización»- con la comunidad académica (charlas, talleres, jornadas informativas) e indicaron así su rol activo en informar los alcances de la ley en el marco de actividades de difusión del repositorio. Observamos en varios testimonios un fuerte nivel de compromiso de estos actores con la difusión de la normativa y el acceso abierto en general, así como también la utilización de las implicancias de la ley como estrategia para posicionar al repositorio en la comunidad.

En cuanto a la reacción, si bien coincidieron en señalar que en general las y los investigadores adhieren y están de acuerdo con los postulados del acceso abierto, en varios casos marcaron la existencia de perfiles más reticentes. Las objeciones que perciben, o han recibido, se relacionan con la obligatoriedad de depósito, el desconocimiento mismo de la ley, la «visión cerrada» respecto del AA, los derechos de autor y las prácticas de publicación disciplinares:

Si bien la ley es ampliamente conocida por los docentes e investigadores, esta no deja de producir algunas controversias en cuanto al derecho de autor. Si bien la Universidad propicia el libre acceso a la información, algunos pocos estudiantes, investigadores y docentes son un poco reticentes a publicar en este tipo de acceso abierto. (E19) 
Entre los factores que hacen a los y las investigadores estar más o menos predispuestos a cumplimentar el depósito de las producciones en el repositorio en tiempo y forma, señalaron la edad del investigador y/o su trayectoria -indicando que los más jóvenes están más comprometidos-, y también la menor dedicación horaria como factor que genera «poco involucramiento». Otro gestor nombró este mismo aspecto como obstáculos «generacionales» e hizo alusión a las nuevas generaciones como disruptoras de las prácticas tradicionales de comunicación. También se mencionó la existencia de grupos que suelen transformarse en agentes activos de difusión:

También hay un grupo minoritario que adhiere muchísimo al repositorio y al acceso abierto, con los cuales hemos podido trabajar. Hemos localizado algunos investigadores que son pro-AA, con los cuales tenemos charlas e incluso envían material para subir. Eso es un buen elemento que hemos trabajado bastante. Apoyarnos en aquellos que apoyan el AA y ahí empezar a difuminar nuestra filosofía. (E36)

Algunos entrevistados hicieron alusión a la convivencia con otras infraestructuras de comunicación científica como son los sitios de redes sociales (ResearchGate, Academia, entre otros). En un caso, apuntándolo como oportunidad al despertar el interés en la difusión y en conocer el impacto de su producción, mientras que en otros se notó cierto descontento ante la preferencia de esta práctica por parte de las y los investigadores:

Tienen poco conocimiento no solo de la ley, sino de todo lo referido al depósito, comunicación y protección de trabajos. En los últimos años y por diferentes iniciativas, los usuarios se abrieron a nuevas formas de comunicar sus trabajos en distintas plataformas externas (ResearchGate, Academia.edu, etc.). Al parecer son más partidarios de depositar en estos sitios que en sus propios repositorios. (E10)

En relación con los intereses de las y los investigadores, algunos gestores -que coinciden con los repositorios de más trayectoria- señalaron la importancia de ofrecer «incentivos», más allá de los mandatos que rigen, como estrategia para la tracción de trabajos y la conformación de comunidades sumando servicios de valor añadido, como por ejemplo estadísticas de uso y asignación de identificadores a los documentos (DOI e ISBN a las tesis).

Finalmente, debemos mencionar la alusión a la temática de los datos primarios. En general en algunas entrevistas se deja entrever que la puesta a disposición de los datasets parece revestir una alta complejidad tanto para las 
y los autores como para las y los gestores. Esto queda plasmado en los testimonios, por ejemplo, cuando hacen referencia a las dificultades suscitadas en la elaboración del plan de gestión de datos para cumplir con la adecuación a la legislación.

\subsection{Articulación con otras iniciativas}

En las entrevistas indagamos sobre la existencia de una editorial o área de edición en la dependencia (universidad/facultad/departamento), y en caso afirmativo, cuál era su relación con el repositorio. En 33 casos las y los entrevistados señalaron que contaban con una editorial universitaria establecida o en formación -que publicaba mayormente libros-, o al menos un área o sector de publicaciones que se vinculaba con el repositorio:

La Facultad edita regularmente dos revistas científicas y un informe de coyuntura. Las tres publicaciones se encuentran alojadas dentro del repositorio y la totalidad de sus contenidos está dispuesta en acceso abierto. La vinculación es directa porque el «equipo del repositorio» (dos personas) trabajan en forma conjunta con los consejos editoriales de las publicaciones editadas. (E32)

En la mayor parte de las respuestas se observó que los repositorios incluyen todas las publicaciones de las editoriales propias cuando son digitales y de acceso abierto. En aquellas donde sigue siendo prioritaria la edición en papel, con una expectativa de comercialización, puede demorarse su inclusión:

A principio de este año avanzamos en conversaciones (con el actual gerente de la editorial) planteándole que sería estratégico para la visibilidad de la producción de la universidad crear una pasarela que comunique el sistema editorial con el repositorio y que se difunda toda la producción a través de esa plataforma. Por su parte el gerente manifestó una clara postura de «recaudar» como estrategia de posicionar nuevamente a la editorial. Si bien parecen posturas incompatibles, se podría llegar a algún acuerdo, mediante embargo, estableciendo un tiempo para que la publicación esté destinada a la venta y luego pase a estar en acceso abierto en el repositorio. (E29)

Hubo pocos casos en los que se mencionó escasa o nula articulación con las áreas editoriales, pero más como un tema pendiente en el que aún no se había avanzado. En otros, en cambio, la articulación se hacía más notoria con la dedicación en el repositorio de un espacio creado específicamente para la editorial: 
La Universidad tiene una editorial propia y estamos incluyendo publicaciones de la editorial en el repositorio, con licencias CCํํy y están en abierto (...) Estamos haciendo un rastreo de todas las publicaciones de AA y la estamos subiendo porque ya está la reglamentación y el mandato que tenemos. Con la editorial no tenemos algo formal, escrito pero hemos subido libros de AA de la editorial que ya están publicados y difundidos en esa forma. (E36)

En los casos de universidades y facultades con una producción editorial cuantiosa y de larga tradición, pareciera ser que la inclusión de las obras en el repositorio es más lenta ya que los responsables de las editoriales lo ven como un factor que podría afectar la capacidad de venta de las publicaciones. En cambio, en otras, la inclusión de las obras en el repositorio se da de forma casi natural y sin necesidad de articulación previa. Inclusive en un caso se mencionó que las obras digitales editadas se archivan y acceden directamente desde el repositorio.

Además de las editoriales, indagamos sobre la articulación del repositorio con el resto de las iniciativas AA existentes en la institución. Sobre esto, treinta gestores entrevistados dijeron convivir con portales de revistas $u$ otros repositorios, en algunos casos centrales, de facultades/dependencias, o bien especializados en temas o de tipologías documentales determinadas. Salvo pocos casos, la mayoría articulan entre sí, y si aún no lo han hecho, ha sido por falta de tiempo o recursos, aunque por lo general lo tienen entre sus próximos planes:

Existe un portal de revistas institucionales y su existencia es previa a la creación del repositorio. Se planifica incorporar el contenido de dicho portal al repositorio en el mediano plazo, ya que actualmente no existe una relación entre los contenidos ni siquiera en lo relativo a la consulta de los usuarios finales. (E35)

En varias UUNN observamos el modelo combinado de portal de revistas en AA -administrado con el software OJS- y repositorio institucional para el resto de la producción científico-académica -administrado con DSpace-, un esquema bastante común también en otras universidades de la región y del mundo. En la mayoría de esos casos, la coordinación de actividades conjuntas es la norma y es bastante frecuente que los equipos que gestionan ambas iniciativas sean los mismos.

\subsection{Cumplimiento de los requerimientos de la ley}

En el recorrido por la web observamos que de los 46 repositorios institucionales en funcionamiento, el 72\% (33) contaba con alguna normativa relacionada, 
por lo general resoluciones de creación y criterios básicos de organización y funcionamiento. De ellos, solamemte 7 habían logrado aprobar una política de acceso abierto de acuerdo con los requerimientos estipulados en la reglamentación de la ley (Res. 753/2016). En las entrevistas algunos gestores comentaron las dificultades que tuvieron para lograr su aprobación; otros, la necesidad de actualizar aquella versión aprobada antes de 2016, y los restantes informaron estar trabajando en el tema para lograr su aprobación:

Sí, hemos sancionado una Política de Acceso abierto en el año 2015. Fue difícil su aceptación ya que investigadores y doctorandos muchas veces consideran sus trabajos como resultado de sus esfuerzos y no como resultado de actividades de investigación y capacitación brindada en la universidad pública, y priorizan su publicación en editoriales privadas. No hemos realizado ninguna actualización, tendríamos que hacerlo. (E31)

En cuanto a la falta de adecuación de las políticas institucionales a la ley, las y los gestores señalaron como razones posibles el desconocimiento cabal de la normativa y el resquemor que produce la obligatoriedad del depósito como algo compulsivo:

Las autoridades conocen la ley pero son renuentes a formular una política institucional. Las razones explícitas se sitúan en el rechazo a cargar a los investigadores con mayores tareas administrativas y las dificultades que implica la relación con las editoriales. (E27)

Un grupo menor evidenció dificultades para hacer que las políticas se efectivicen y, sobre todo, logren continuidad y se sostengan en el tiempo ante los cambios de gestión.

En otra pregunta específica indagamos acerca de los principales obstáculos que percibían para el cumplimiento de la ley. Como era esperable, una de las «barreras» más indicadas fueron las presupuestarias en relación con la falta de recursos para incorporar personal y formarlo, como así también para emprender tareas de fortalecimiento y mejoramiento. Diez gestores señalaron además distintas problemáticas relacionadas con la coordinación y articulación de los repositorios con distintas áreas internas y con la estructura organizacional para favorecer la ingesta y su consolidación como infraestructura.

En once oportunidades las y los gestores mencionaron, entre los obstáculos, diferentes aspectos del modelo de comunicación científica hegemónico o de las prácticas de las y los investigadores en cuanto a la publicación y 
difusión de sus trabajos, tales como las lógicas propias del campo disciplinar, los modos de reconocimiento y los sistemas de evaluación que condicionan sus prácticas:

No hay un conocimiento profundo sobre opciones de depósito, publicación, distribución y protección de obras. El principal obstáculo es la formación e información sobre estos aspectos, sumado a prácticas de arrastre cultural. En particular, al no contar aún con mandatos propios, la fuga de trabajos o su depósito exclusivo en otras plataformas dificultan el crecimiento sostenido de nuestro repositorio y dispersan la producción en sitios de origen o dominio comercial. (E10)

En ciencias naturales, considero que hay mucha competencia para publicar en revistas de alto impacto, por lo que los autores no están en condiciones (o lo desconocen) de otorgar licencias no exclusivas de publicación, lo que influye en el porcentaje de publicaciones disponibles en acceso abierto en los repositorios. (E28)

Otro aspecto mencionado en las entrevistas son los inconvenientes que trae aparejada la legislación internacional de propiedad intelectual para la circulación del conocimiento, ya que habilita a las editoriales a exigir a las y los autores la cesión exclusiva de sus derechos patrimoniales. Algunos entrevistados indicaron la necesidad de adecuar el régimen de propiedad intelectual vigente para favorecer la política de acceso abierto y formar a las y los investigadores en torno a estos temas. Por otro lado, diez gestores hicieron mención al hecho concreto de generar y/o actualizar normativas propias e instrumentos varios para establecer el mandato como política institucional.

En cuanto a los datos primarios, solo tres entrevistados mencionaron la dificultad de cumplimentar esta parte de la normativa, y plantearon dos aspectos: las resistencias de las y los investigadores y la complejidad de su gestión que consideran que requerirá el armado de equipos interdisciplinarios. Pudimos ver en algunos testimonios que avanzar hacia la disponibilidad de los datos pareciera ser una tercera instancia de desarrollo a abordarse, posterior a la consolidación del repositorio y la aprobación de la política de acceso abierto.

\subsection{Respecto al funcionamiento del SNRD}

Las consideraciones e inquietudes respecto del SNRD pueden agruparse en dos categorías: por un lado, el funcionamiento del Sistema en sí, y por otro lado, las posibilidades y dificultades de concreción de las líneas de financiamiento que ofrece a los repositorios. En la función de orientación y coordinación de los repositorios y las instituciones que los sostienen, además de experiencias en las 
que se valora la asistencia brindada, también se reclama un mayor seguimiento y evaluación en el cumplimiento de las directrices para los proveedores del Sistemạ, que se asesore especialmente en la obtención y gestión de datos primarios de la investigación y en el seguimiento de las normas de interoperabilidad, que se implementen procesos más ágiles para la adhesión al Sistema y la cosecha de metadatos, que se reciba asesoramiento para recuperar trabajos que las y los autores han cedido a las editoriales y que se contemple la heterogeneidad del software empleado por las instituciones.

La duplicación de esfuerzos de registro y depósito de los resultados de la investigación entre los repositorios, el SIGEVA y el CVAR, se señala también como problema y necesidad de articulación.

Frente a la falta de control del grado de cumplimiento de la ley de repositorios por parte de las universidades, en varias oportunidades las y los gestores solicitaron la intervención del SNRD ante las autoridades de las instituciones y la aplicación de mecanismos y requisitos tales como la exigencia de la sanción de políticas institucionales de acceso abierto para otorgar financiamiento.

Las líneas de acción del SNRD respecto del control de la aplicación de la ley son insuficientes. Por ejemplo, sabemos que han remitido notas a las autoridades superiores de las universidades, pero esos llamados de atención no llegan nunca a las facultades en universidades grandes, ni a los investigadores y docentes. (E27)

En estrecha vinculación con este tema, se hallaron expresiones de la conciencia sobre la interdependencia entre los criterios de evaluación de la investigación científica y los porcentajes de cumplimiento del depósito de los trabajos por parte de las y los investigadores, reclamándose sistemas de premios y castigos como forma de incentivo:

Para quebrar la resistencia de los autores a depositar su producción científica en los repositorios en acceso abierto, sería necesario articular la ley y su regulación con las evaluaciones a los investigadores, es decir, valorar positivamente cuando un investigador disponga y difunda su producción en acceso abierto más que valorar por la publicación que realice en revistas de alto impacto. (E29)

Otra idea manifiesta, frente a la preocupación por el bajo índice de autoarchivo, fue la necesidad de explorar vías alternativas de obtención de artículos tales como la importación desde portales comerciales de información científica. 
Se enfatizó la importancia de que el Comité de Expertos retome su rol de asesor y colaborador en la elaboración de políticas y líneas de acción y el establecimiento de instancias para que puedan escucharse las situaciones y requerimientos de todos los repositorios del Sistema, señalándose la parálisis parcial de estas funciones desde 2016 a 2019.

También se encontraron solicitudes para que el SNRD organice más actividades de capacitación y sensibilización de investigadores, becarios, docentes y autoridades respecto del Sistema, sus funciones y sobre el acceso abierto en general.

Sería interesante que se promuevan programas o campañas de capacitación para investigadores, tecnólogos, docentes, becarios de posdoctorado y estudiantes de maestría y doctorado. Desde nuestra biblioteca se promueven diferentes instancias de formación e información a los usuarios de nuestra unidad académica, pero faltaría un auspicio o apoyo del Sistema Nacional. Si se contara con ese auspicio y promoción, la participación sería mayor. Si bien podría formar parte de una política institucional, sería de gran ayuda el apoyo a todo el sistema universitario y/o el de ciencia y técnica a nivel nacional. (E10)

Se hallaron, asimismo, solicitudes de que se contemple la incorporación de la vía dorada (portales de revistas y libros en abierto) al SNRD y que se ajuste la normativa en el sentido de flexibilizar los tiempos de depósito por el embargo que imponen las editoriales comerciales de información científica.

Respecto al uso de las líneas de financiamiento del SNRD, de los cuarenta entrevistados, solo nueve habían solicitado financiamiento al Sistema. Del resto, ocho manifestaron su intención de hacerlo próximamente. Hasta el momento de la entrevista se habían aprobado ocho proyectos: cinco de creación y tres de fortalecimiento.

Además de algunos reclamos sobre mayor difusión de las líneas de financiamiento ofrecidas $\underline{\underline{10}}$, las y los entrevistados mencionaron distintas dificultades para obtenerlo, que agrupamos en tres categorías. La primera, relacionada con la formulación de los proyectos: los gestores indicaron la escasez de recursos, experiencias o conocimientos para elaborarlos; las limitaciones de las líneas habilitadas en relación con las necesidades de los repositorios; la imposibilidad de trabajar en conjunto con varias instituciones; los requerimientos establecidos por el Banco Interamericano de Desarrollo (BID) -que es la fuente de financiamiento internacional para estos proyectos-, especialmente el impedimento para contratar consultores de las instituciones que pertenecen al SNRD, situación que se profundiza aún más al aumentar la 
cantidad de instituciones adheridas; y por último, el inconveniente para cubrir el porcentaje requerido de la contraparte. La segunda categoría de dificultades se relaciona con la ejecución y rendición de los proyectos, donde las y los gestores señalaron los complejos procedimientos para las licitaciones de equipamiento o la obtención de proveedores que coticen el equipamiento solicitado en un contexto de permanente inestabilidad monetaria. También se comentaron problemas para otras etapas de la ejecución de los proyectos de financiación, tales como la rendición de cuentas. La tercera refiere a obstáculos propios de las instituciones, como la falta de apoyo de las autoridades, las complicaciones para reunir información sobre la producción científica institucional y la inadecuación de la normativa institucional para la formulación o la ejecución de proyectos de financiación que ofrece el SNRD.

Finalmente, se destacaron sugerencias de mayor trabajo interinstitucional, que incluya también a las editoriales, y se citó como ejemplo los valiosos resultados obtenidos en los proyectos PICT-O CIN mencionados en el punto 3, que convocaron al trabajo conjunto interuniversitario. Asimismo, se subrayó la importancia de la creación de instancias articuladoras dentro de las instituciones tales como comités o comisiones de acceso abierto, que nuclean a todos los actores de la comunicación científica, lo que habilitó la consideración de requerimientos y prácticas heterogéneas, el logro de consensos y la elaboración de políticas institucionales.

\section{Discusión y conclusiones}

Con esta indagación pudimos corroborar que las políticas públicas implementadas en Argentina en los últimos años, que tuvieron su epicentro en el SNRD, han favorecido notablemente el desarrollo de los repositorios institucionales en las UUNN. Del análisis se desprende que la ley constituyó un hito fundamental y que las otras políticas han marcado el pulso de la evolución de los repositorios acelerando procesos hacia el interior de las instituciones, hecho que queda demostrado por el tamaño que han conseguido varios repositorios de reciente creación.

Asimismo, pudimos distinguir dos períodos en el desarrollo de los repositorios institucionales en funcionamiento. El primero, que va de 2003 a 2013, en el que comenzaron a gestarse iniciativas generalmente impulsadas por bibliotecarios en pos de favorecer el AA (Fushimi, 2018), cuyos actores fueron convocados por el Estado nacional para conformar las bases del SNRD. El segundo periodo, que abarca de 2014 a 2019, signado por las políticas públicas, en donde se gestan un número considerable de repositorios (el $65 \%$ de los 
relevados) y en el cual los existentes trabajan para adecuarse. Esto sucede en un contexto institucional, que según la percepción de las y los gestores está en tensión por las prácticas de publicación y evaluación nacionales arraigadas en los diferentes campos disciplinares y en las culturas evaluativas institucionales -percepción que coincide con estudios empíricos del campo científico argentino (Beigel, 2015, 2017)-, al tiempo que permanece permeable a incorporar políticas de apertura.

Por otro lado, la opinión de las y los gestores permitió observar cómo se interrelacionan las políticas públicas con las realidades en las instituciones y el desarrollo y la evolución de los repositorios. En un primer término, se destaca que la ley ha servido como herramienta para consolidar el repositorio -o su proyecto- a través de la adecuación de normativas existentes que promueven su evolución. En segundo término, que la legislación y sus implicancias son desconocidas en distintas esferas institucionales. Las autoridades no siempre prestan el apoyo necesario en los proyectos que son presentados, lo que se traduce en escasos recursos humanos y tecnológicos. Por su parte, las y los docentes-investigadores, sumidos en las vorágines del campo para lograr reconocimiento, financiamiento y avances en su carrera, consideran al autoarchivo una carga burocrática más en coincidencia con estudios previos a la sanción de la ley (Bongiovani et al., 2014). Esto último ha llevado a las y los gestores a desarrollar distintas estrategias, entre ellas, ofrecer servicios de valor agregado que permitan a las y los autores identificar fácilmente su producción y disponer de estadísticas de uso, así como acudir a grupos más comprometidos para sumar a campañas de sensibilización.

En tercer lugar, pudimos ver que la articulación con las editoriales universitarias es algo deseable por las y los gestores, tal como indicaba Fushimi (2018), lo que se evidencia en varios repositorios donde la producción editorial institucional está incluida y en las entrevistas realizadas. También observamos cómo los espacios de circulación ofrecidos por los RI son vistos -en muchos de los casos- como una oportunidad para darle más visibilidad a las obras. La existencia de varias editoriales que disponen en su web de obras monográficas a texto completo habla además de un cambio de paradigma hacia el entorno digital que podría deberse a las posibilidades de difusión que promete la web. En este sentido, Pené et al. (2019) señalaron que quince de las editoriales universitarias detectadas en las UUNN que publican libros electrónicos articulan con los repositorios con -al menos- dos modalidades distintas: la utilización del repositorio como espacio de publicación digital, o su registro y depósito posterior para ampliar la difusión y garantizar su preservación. 
Asimismo, encontramos la convivencia de un número de iniciativas diversas en las universidades, además de los repositorios institucionales, que muestran el interés de los distintos grupos sociales en difundir y visibilizar en la web sus producciones de forma gratuita, muchas de ellas relacionadas con la publicación de obras científicas que responden a la vía dorada. Las editoriales y los portales de libros y revistas detectadas en el relevamiento $\underline{\underline{11}}$ suponen la necesidad de pensar otras herramientas legales que, impulsadas por el Estado, respalden la edición universitaria generando infraestructuras que favorezcan la soberanía del conocimiento (Banzato, 2019).

Otra cuestión observada en este trabajo fue la situación de los repositorios de datos como artefacto en sí mismo, ya que no están siendo desarrollados como se estipulaba en la ley. Detectamos, en algunos casos, la incorporación de set de datos como una colección más de los repositorios existentes, hecho que dejaría en manos del SNRD el desarrollo de visualizadores que permitan aprovechar y reutilizar esos datos. En esta dirección se encuadraría el recientemente lanzado portal de Datos Primarios en Acceso Abierto de la Ciencia y la Tecnología Argentina (DACYTAr) en el marco del sistema nacional $\underline{\underline{12}}$.

Finalmente, para que la producción científica generada con fondos públicos esté disponible de forma inmediata, gratuita y libre para cualquier persona que requiera su uso es necesario reforzar los roles y las funciones de cada actor involucrado. Por un lado, que el Estado -en su rol de órgano de aplicación de la ley-ejerza mayor control para monitorear en territorio las realidades y dificultades existentes. Por ejemplo, realizando un diagnóstico a nivel de las UUNN para explicitar las dificultades de los distintos grupos, buscar soluciones posibles y alcanzar la adecuación de las instituciones a la política, función que podría ser coordinada por el Comité de Expertos del SNRD. Por otro, que las autoridades de cada universidad y sus dependencias se comprometan y elaboren estrategias para agilizar e impulsar la concreción de las políticas. Y también que las y los docentes e investigadores, como productores de contenidos, tomen conciencia de que transfieren en forma gratuita a las editoriales comerciales el producto de su propio esfuerzo cuando no disponen sus trabajos en acceso abierto, y asuman el papel esencial que les cabe en el depósito de su producción en los repositorios institucionales.

Como reflexión final en esta coyuntura institucional y política, consideramos que los repositorios deberían ser infraestructuras que, a la par de favorecer la reunión y visibilidad de la producción científica, se constituyan en fuentes consistentes para el cálculo de diferentes indicadores de ciencia y tecnología como base de la evaluación de la ciencia nacional. Su función de 
reunión se podría resignificar, y la accesibilidad de los textos y datos podría constituir un punto de partida para el desarrollo de nuevas tecnologías que posibiliten la medición de procesos y no solo de productividad.

\section{Agradecimientos}

Los resultados expresados en este artículo son producto del trabajo realizado en el proyecto de investigación Repositorios digitales de acceso abierto en las universidades nacionales argentinas: Desarrollo, evolución y perspectivas de futuro (Código H040, período 2018-2019) financiado por la Universidad Nacional de La Plata, que tuvo curso en el Instituto de Investigaciones en Humanidades y Ciencias Sociales que depende de la Universidad Nacional de La Plata y el CONICET (Argentina). Agradecemos a Marina Borrell, Milagros Martínez, Carolina Mazza, Carolina Monti, Nadia Buckmeier, Angela Paladino y Martín Williman, quienes integraron también el equipo del proyecto. Asimismo, queremos agradecer a las y los gestores que prestaron su tiempo para las entrevistas.

\section{Notas}

1. El movimiento de acceso abierto a la literatura científica (open access) propone que los usuarios puedan leer, descargar, copiar, distribuir, imprimir, buscar o enlazar los textos completos de los artículos científicos y usarlos con cualquier propósito legítimo, sin que medien barreras económicas, legales o técnicas más que las que supone Internet en sí misma (Budapest Open Access Iniciative, 2002). « VOLVER

2. Como por ejemplo, las licencias Creative Commons (http://www.creativecommons. org.ar/), cuyo uso es el más extendido para favorecer la reutilización de contenidos disponibles en la web. « VOLVER

3. Excluimos de esta categoría las páginas o sitios web que contenían solamente un título de revista. « vOLVER

4. OpenAire (https://www.openaire.eu/) es un portal de la comunidad europea que pretende reunir -a través de la cosecha de metadatos- la literatura científica mundial, ya que incluye en su recolección no solo repositorios sino también revistas, archivos y otros proveedores de recursos científicos en acceso abierto de todo el mundo, incluyendo al Portal latinoamericano LA Referencia (http://www.lareferencia.info/es/). « VoLVER

5. A la fecha, son 68 las instituciones universitarias nacionales y provinciales asociadas al CIN [Fecha de consulta: 2/9/2020]. « VOLVER

6. En diecinueve UUNN no se encontraron iniciativas: UN Noroeste de la Provincia Buenos Aires, UN San Antonio de Areco, U Provincial de Córdoba, IUN de Derechos Humanos «Madres de Plaza Mayo», IU Policía Federal Argentina, IU Seguridad Marítima, UN Tres de Febrero, UN Almirante Brown, UN Lomas de Zamora, UN del Oeste, UN José C. Paz, UN San Isidro 
Raúl Scalabrini Ortiz, UN Alto Uruguay, UN Chaco Austral, UN Formosa, UN de los Comechingones, UN Villa Mercedes, IU Patagónico de Artes y UN Hurlingham. « VOLVER

7. Conocidas como las tres BBB, las declaraciones de Budapest (2002), Bethesda y Berlín (2003) son consideradas las fundadoras del movimiento internacional de acceso abierto a la literatura científica. « voLvER

8. CC: Creative Commons (https://creativecommons.org/). « VOLVER

9. Estas directrices especifican los requisitos técnicos que un repositorio debe cumplir para sumarse al SNRD e interoperar con otros sistemas nacionales e internacionales. El texto completo puede consultarse en https://repositoriosdigitales.mincyt.gob.ar/files/Directrices SNRD 2015.pdf « VOLVER
10. Los requerimientos se modificaron posteriormente, a comienzos de 2020: https:// repositoriosdigitales.mincyt.gob.ar/vufind/ Content/financiamiento « VOLVER

11. Salatino (2019) identificó quinientas revistas activas entre 2016/2017 editadas por las universidades, el $41 \%$ de las publicadas en el país, lo cual da cuenta de la relevancia de este sector para la comunicación de la ciencia. « VOLVER

12. Fue difundido a mediados de octubre de 2020. En su web (https://dacytar.mincyt.gob. ar/), al 27 de octubre de 2020, están incluidos 319 set de datos, de seis repositorios, cuatro de ellos de las UUNN: SEDICI (UNLP) -que aporta la mayor parte de los documentos (293)-, RID-UNRN (UNRN), Repositorio Digital Universitario (UNC) y RepHiPUNR (UNR). « VOLVER

\section{Referencias bibliográficas}

ANDRÉS, G.; Cortassa Amadio, C.; Wursten, A. y Legaria, J. I. (2020). Repositorios institucionales digitales de acceso abierto: una mirada socio-tecnológica: Estudio de caso del repositorio de la Universidad Nacional de Entre Ríos - Argentina. Información, Cultura y Sociedad, (42), 35-52. DOI: https:// doi.org/10.34096/ics.i42.7404

BANZATO, G. (2019). Soberanía del conocimiento para superar inequidades: políticas de Acceso Abierto para revistas científicas en América Latina. Sao Paulo. Mecila Working Papers. Disponible en: http://mecila.net/wp-content/uploads/2019/08/ WP-18-Banzato-Online-Final.pdf
BEIGEL, F. (2015). Culturas [evaluativas] alteradas. Política Universitaria, 2, 11-21. Disponible en: http://hdl.handle.net/11336/43518 BEIGEL, F. (2017). Científicos Periféricos, entre Ariel y Calibán. Saberes Institucionales y Circuitos de Consagración en Argentina: Las Publicaciones de los Investigadores del CONICET. Dados, 60(3), 825-865. DOI: https://doi.org/10.1590/001152582017136

BONGIOVANI, P.; Guarnieri, G.; Babini, D., y López, F. (2014). Acceso abierto en la Universidad Nacional de Rosario. Necesidades y prácticas de los docentes/investigadores. C, 30, 13-33. Disponible en: http://ppct.caicyt.gov.ar/index.php/ics/article/view/4591 
BonGIOVANI, P. y Nakano, S. (2011). Acceso Abierto en Argentina: La experiencia de articulación y coordinación institucional de los repositorios digitales en ciencia y tecnología. e-colabora, Revista de ciencia, educación, innovación y cultura apoyadas por redes de tecnología avanzada, 1(2), 163-179.

BUDAPEST OPEN ACCESS INITIATIVE. (2002, febrero 14). Disponible en: www.budapestopenaccessinitiative.org/read

DE VOLDER, C. (2008). Los repositorios de acceso abierto en Argentina: situación actual. Información, Cultura y Sociedad, 19, 79-98. Disponible en: http://revistascientificas.filo.uba.ar/index.php/ICS/article/view/83

FREITAS, M. y Leite, F. (2019). Atores do sistema de comunicação científica: apontamentos para discussão de suas funções. Informação \& Informação, 24(1), 273-299. DOI: http://dx.doi.org/10.5433/1981-8920.20 19v24n1p273

FUSHIMI, M. y Banzato, G. (2010). Las políticas de acceso abierto en las universidades estatales argentinas: un análisis a través de la web. Ponencia presentada en VI Jornadas de Sociología de la UNLP. La Plata, 9-10 de diciembre de 2010. Disponible en: $w w w$. memoria.fahce.unlp.edu.ar/trab eventos/ ev.931/ev.931.pdf

FUSHIMI, M. (2018). Desarrollo de repositorios digitales institucionales en las universidades nacionales en Argentina, período 2004-2015 (tesis de maestría). Universidad Nacional de Quilmes. Disponible en: www. memoria.fahce.unlp.edu.ar/tesis/te.1629/ te.1629.pdf

FUSHIMI, M. y Unzurrunzaga, C. (2020). Más allá de los repositorios institucionales: iniciativas de acceso abierto en las universidades nacionales argentinas de gestión pública. En Actas de las III Jornadas de Investigación de la Facultad de Información y Comunicación, 4 y 5 de noviembre de 2019, Montevideo, Uruguay. Montevideo: FIC. Disponible en: www.memoria. fahce.unlp.edu.ar/trab eventos/ev.13815/ ev.13815.pdf

GUÉDON, J. C. (2009). It's a repository, it's a depository, it's an archive...: open access, digital collections and value. ARBOR Ciencia, Pensamiento y Cultura, 185 (737), 581-595. DOI: http://dx.doi.org/10.3989/arbor.2009.i737.315

LATTUADA, M. y Giba, G. (2014). Una introducción a la Ley de Repositorios Abiertos para Ciencia y Tecnología. Debate Universitario, 2(4), 79-99. Disponible en: http://ppct. caicyt.gov.ar/index.php/debate-universitario/article/view/4588

LEY 26.899 de 2013, Repositorios digitales institucionales de acceso abierto. Boletín Oficial de la República Argentina, 32.781, Primera Sección, 3-4. Disponible en: http:// servicios.infoleg.gob.ar/infolegInternet/anexos/220000-224999/223459/norma.htm

MAZZA, C. (2019). Construcción social y situación actual de los repositorios digitales institucionales de acceso abierto en la Universidad Nacional de La Plata (tesis de grado). Universidad Nacional de La Plata. Disponible en: www.memoria.fahce.unlp. edu.ar/tesis/te.1629/te.1838.pdf

NAKANO, S. y Azrilevich, P. A. (2017). El acceso abierto y la implementación de la Ley 26.899 en la Argentina. Presentado en VII Conferencia Internacional sobre Bibliotecas y Repositorios Digitales de América La- 
tina (BIREDIAL-ISTEC'17) y XII Simposio Internacional de Biblioteca Digitales (SIBD'17). La Plata, 2-4 de octubre de 2017. Disponible en: http://hdl.handle.net/10915/63553

PENÉ, M. G.; Unzurrunzaga, C. y Borrell, M. (2016). Repositorios institucionales universitarios argentinos, un acercamiento a sus colecciones. Presentado en IV Jornadas de Intercambio y Reflexión acerca de la Investigación en Bibliotecología, La Plata, 29-30 de octubre de 2015. Disponible en: www.memoria.fahce.unlp.edu.ar/trab eventos/ev.5293/ev.5293.pdf

PENÉ, M.; Unzurrunzaga, C. y Borrell, M. (2019). Editoriales universitarias argentinas y acceso abierto: análisis y reflexión acerca de la oferta de libros electrónicos y su inclusión en repositorios institucionales. Presentado en 17a Jornada sobre la Biblioteca Digital Universitaria «Diversidad en los servicios, servicios para la diversidad», Ciudad Autónoma de Buenos Aires, 7-8 de noviembre de 2019.

PINCH, T. J. y Bijker, W. E. (2008). La construcción social de hechos y artefactos: $\mathrm{O}$ acerca de cómo la sociología de la ciencia y la sociología de la tecnología pueden beneficiarse mutuamente. En Actos, actores y artefactos: Sociología de la tecnología (pp. 19-62). Bernal: Universidad Nacional de Quilmes.

RESOLUCIÓN 469 de 2011 [Ministerio de Ciencia, Tecnología e Innovación Productiva].
Aprueba la creación del Sistema Nacional de Repositorios Digitales y establece sus objetivos, estructura y organización. 17 de mayo de 2011.

RESOLUCIÓN 753 de 2016. [Ministerio de Ciencia, Tecnología e Innovación Productiva]. Reglamentación de la Ley 26.899 sobre Creación de Repositorios Digitales Institucionales de Acceso Abierto. Disponible en: www.argentina.gob.ar/normativa/nacional/ resoluci\%C3\%B3n-753-2016-267833/texto

Salatino, M. (2019). Las encrucijadas de las revistas universitarias en Argentina. En Fernanda Beigel y Fabiana Bekerman (coords.), Culturas evaluativas: Impactos y dilemas del Programa de Incentivos a Docentes-Investigadores en Argentina (19932018) (pp. 115-138). Ciudad Autónoma de Buenos Aires: CLACSO, CECIC, IEC-CONADU. Disponible en: http://biblioteca.clacso.edu. ar/clacso/se/20191125105317/Culturas-evaluativas.pdf

UnZURRUnZAGA, C.; Fushimi, M., Pené, M. y Sanllorenti, A. (2019). La vía verde del acceso abierto en Argentina: evolución y desarrollo de los repositorios en las universidades nacionales. En Actas del IX Conferencia Internacional sobre Bibliotecas y Repositorios Digitales de América Latina, 30 de julio al 2 de agosto de 2019, San Pablo, Brasil. Disponible en: www.memoria. fahce.unlp.edu.ar/trab eventos/ev.13719/ ev.13719.pdf 


\section{Anexos}

\section{Preguntas de la entrevista}

1. ¿Qué influencia/s tuvo la sanción de la ley 26.899 en la creación y/o el desarrollo del repositorio de su institución?

2. ¿Considera que la comunidad de docentes/investigadores de la institución tiene conocimiento de la ley y de sus implicancias? ¿Podría comentarnos, según su opinión, cuáles fueron sus principales reacciones (conocen, adhieren, participan, rechazan, depositan)?

3. Si su institución tiene una editorial propia, ¿está prevista la inclusión de sus publicaciones en el repositorio? ¿Cómo es la vinculación entre el repositorio y la editorial?

4. ¿Cuáles son los principales obstáculos que observa en su institución para avanzar en el cumplimiento de lo estipulado en la ley?

5. ¿Su institución ha sancionado una política de acceso abierto que adecue el cumplimiento de la ley a las características propias? ¿Qué dificultades tuvo? Si ya la tenía formulada antes de la reglamentación de la ley en 2016, ¿han realizado modificaciones al texto con posterioridad?

6. ¿Con qué objetivo/s han solicitado o piensan solicitar financiamiento al SNRD? ¿Cuáles fueron las dificultades con que se toparon? Si no lo han hecho, ¿podría indicarnos los motivos?

7. Si hay más de un repositorio y/o iniciativa de acceso abierto (portal de revistas, de libros, de recursos de aprendizaje, etc.) en su institución, ¿podría comentarnos cómo es la relación con el repositorio y describir las formas de articulación o trabajo conjunto -si lo hubiera-?

8. Comentarios. Si quiere puede dejarnos otras impresiones respecto de la ley, el sistema nacional de repositorios y las líneas de financiamiento.

\section{Lista de instituciones y repositorios a los que pertenecen los gestores entrevistados}

\begin{tabular}{l|l}
\hline UUNN & Nombre iniciativa \\
\hline IUGNA & REDIG \\
\hline UBA & RDI-UBA Repositorio Digital Institucional \\
\hline UBA. FA & FAUBA Digital \\
\hline UBA. FCE & Biblioteca Digital \\
\hline UBA. FCEN & Biblioteca Digital \\
\hline UBA. FFL & Filo Digital \\
\hline UnaM & RIDUNaM: Repositorio institucional de la Universidad Nacional de Misiones \\
\hline
\end{tabular}




\begin{tabular}{|c|c|}
\hline UNC & Repositorio Digital \\
\hline UNC. FFyL & Ansenuza \\
\hline UNCA FTyCA & Repositorio Institucional para la FTyCA de la UNCA (RITEYCA) \\
\hline UnCoMA & Lenguas. Biblioteca digital \\
\hline UnCoMA & RDI-UNCo \\
\hline UnCoMA & Repositorio digital FATU \\
\hline UNCuyo & Biblioteca Digital \\
\hline UNDEF & Repositorio Digital Universitario \\
\hline UNER & RIUNER. Repositorio Institucional de la Universidad Nacional de Entre Ríos \\
\hline UNICEN. FCH & ReDiHum: Repositorio digital de Ciencias Humanas \\
\hline UNLa & Repositorio Digital Institucional José María Rosa \\
\hline UNLAM & Repositorio Digital UNLaM \\
\hline UNLP & SEDICI Servicio de Difusión de la Creación Intelectual \\
\hline UNLP. FaHCE & Arcas \\
\hline UNLP. FaHCE & Memoria Académica \\
\hline UNLP. FAU & Biblioteca Digital Arq.Hilario Zalba \\
\hline UNLP. FCNyM & Naturalis \\
\hline UNLPAM & ReDi: Repositorio Digital de la FCEYN - UNLPAM \\
\hline UNLPAM & Repositorio Digital de Acceso Abierto \\
\hline UNLu & Repositorio digital institucional REDIUNLu \\
\hline UNMdP. FCEyS & Nülan \\
\hline UNMdP. FH & HumaDoc \\
\hline UNMdP. Psico & RPsico \\
\hline UNNE & RIUNNE \\
\hline UNQ & RIDAA: Repositorio Institucional Digital de Acceso Abierto de la UNQ \\
\hline UNR & RepHipUNR: Repositorio Hipermedial \\
\hline UNRaf & Repositorio UNRaf \\
\hline UNRN & Repositorio Digital Institucional \\
\hline UNS & Repositorio institucional de la UNS \\
\hline UNSa & RIUNSA - Repositorio Institucional de la Universidad Nacional de Salta \\
\hline UNSAM & Repositorio institucional \\
\hline UNVM & Repositorio Digital Universidad Nacional de Villa María \\
\hline UTN & Repositorio Institucional Abierto \\
\hline
\end{tabular}

